\title{
Gadolinium(III)-Incorporated Nanosized Mesoporous Silica as Potential Magnetic Resonance Imaging Contrast Agents
}

\author{
Yu-Shen Lin, ${ }^{\dagger}$ Yann Hung, ${ }^{\dagger}$ Jen-Kuan Su, ${ }^{\dagger}$ Rain Lee, ${ }^{\ddagger}$ Chen Chang, ${ }^{\ddagger}$ Meng-Liang Lin, ${ }^{\dagger}$ and \\ Chung-Yuan Mou*,,$\S$ \\ Department of Chemistry, National Taiwan University, Taipei, Taiwan 106, Center for Condensed Matter \\ Sciences, National Taiwan University, Taipei, Taiwan 106, and Institute of Biomedical Sciences, \\ Academia Sinica, Taipei, Taiwan 115
}

Received: May 19, 2004; In Final Form: July 20, 2004

\begin{abstract}
A new class of potential magnetic resonance imaging contrast agents with nanosized mesoporous silica as the metal carrier is reported. Gadolinium-incorporated mesoporous silicas were synthesized by using longchain surfactant as a template. The products were characterized with X-ray powder diffraction, nitrogen adsorption-desorption isotherms, high-resolution transmission electron microscopy, X-ray photoelectron spectroscopy, ${ }^{29} \mathrm{Si}-\mathrm{MAS} \mathrm{NMR}$, and proton relaxivity. The materials showed much higher relaxivities, $r_{1}$ and $r_{2}$, than Gd-DTPA. The particles are nanosized and can enter cells easily. This is a completely novel biomedical application of mesoporous silica materials.
\end{abstract}

\section{Introduction}

Over the years magnetic resonance imaging (MRI) has emerged as a widely used clinical diagnostic technique. MRI is noninvasive, it detects morphological and functional change, and is most sensitive for soft tissue. MRI contrast agent is used to improve the contrast between normal and diseased tissues, and to indicate the status of organ function or blood flow. With the application of contrast agent, MRI has been used not only in the brain and spine but also in whole body imaging to detect tumor, infection, and infarction, and also is replacing computed tomography (CT) for blood vessels (MR angiography). The development of MRI contrast agents has attracted great attention on gadolinium because of its large number of unpaired electrons and relatively long electronic relaxation. ${ }^{1-3}$ To be effective, MRI contrast agents must have a strong effect on the longitudinal $\left(1 / T_{1}\right)$ and transverse $\left(1 / T_{2}\right)$ relaxation rate of water proton. To design the contrast agent two parameters are usually considered, increasing the rotational correlation time by increasing molecular weight and size or increasing the number of coordinated waters. Although manganese complex and iron oxide have been approved as MRI contrast agents, ${ }^{4,5}$ commercial contrast agents have been dominated by gadolinium complexes such as Magnevist $\left(\left[\mathrm{Gd}(\mathrm{DTPA})\left(\mathrm{H}_{2} \mathrm{O}\right)\right]^{2-}\right.$, where DTPA is diethylenetriaminepentaacetic acid), Dotarem $\left(\left[\mathrm{Gd}(\text { DOTA })\left(\mathrm{H}_{2} \mathrm{O}\right)\right]^{-}\right.$, where DOTA is 1,4,7,10-tetraazacyclododecane-1,4,7,10-tetraacetic acid), etc. ${ }^{6}$ For stability reasons, most of the known contrast agents are with multidentate ligands. Recent evolution of molecular imaging has generated a further demand for more sensitive and targeted contrast agents. ${ }^{7}$ Some of the reported targets are antibodies, receptor ligands, peptides/proteins, and enzyme substrates. Superparamagnetic iron oxides (SPIOs) and ultra-small superparamagnetic iron oxides (USPIOs) with high $T_{1}$ and $T_{2}$ relaxivities are finding more usages in targeted and molecular imaging, especially for $T_{2}$ application in the latter.

\footnotetext{
* Address correspondence to this author. E-mail: cymou@ntu.edu.tw

† Department of Chemistry, National Taiwan University.

$\doteqdot$ Institute of Biomedical Sciences, Academia Sinica.

$\S$ Center for Condensed Matter Sciences, National Taiwan University.
}

Mesoporous silica would be an excellent carrier for the metal. It is porous: water can freely move in and out of the frame, yet the rigidity of the frame would impede the rotational movement of the metal and improve the relaxation of water. Additionally, the nontoxic silica can be easily derivatized and targeted contrast agents can be synthesized. Nanosized silicas, with a size of less than $100 \mathrm{~nm}$, are small enough to pass through the body, and also are able to enter cells. Nanosized porous silica, as a container, can deliver drugs with gate control to cells $;{ }^{8}$ with MRI capability one can thus have a very powerful imaging and drug delivery system. Gd(III) ion exchanged $\mathrm{NaY}$ zeolite had been reported as a gastrointestinal contrast agent. ${ }^{9}$ However, Y zeolite has a pore size of around $13 \AA$, and the small pores hinder the water movements. Also, the extraframework metal ion is held inside the channel mainly by Coulomb interaction, hence it is prone to leaching and the toxic gadolinium hydroxide would form and precipitate out under physiological conditions. Here we report a method to incorporate Gd into the framework of nanosized mesoporous silica and our investigation of its potential as a MRI contrast agent. The covalent bonding between metal and the silica network makes it less susceptible to leaching in contrast to ion-exchanged metal species.

\section{Experimental Section}

Synthesis. All chemicals were purchased from Arcös, and were of reagent grade. The chemicals were used without further purification. In a typical synthesis, $1.60 \mathrm{mmol}$ of cetyltrimethylammonium bromide, $\mathrm{C}_{16} \mathrm{TAB}$, was dissolved in $29 \mathrm{~g}$ of distilled water, and $3.9 \mathrm{~g}$ of $37 \% \mathrm{HCl}$ was added to the vigorously stirred solution at $32{ }^{\circ} \mathrm{C}$. Then $7.2 \mathrm{mmol}$ of tetraethoxysilane (TEOS) was added to the solution. After a few minutes $0.24 \mathrm{mmol}$ of $\mathrm{GdCl}_{3} \cdot 6 \mathrm{H}_{2} \mathrm{O}$ was added to the solution, and the solution was stirred for a few more minutes before it was poured into $300 \mathrm{~g}$ $0.5 \mathrm{M}$ ammonium solution and the final $\mathrm{pH}$ was raised to 9 . The fine-particle precipitates were collected and dried in air at $60{ }^{\circ} \mathrm{C}$, and then it was calcined at $580^{\circ} \mathrm{C}$ in air for $6 \mathrm{~h}$ to remove the templates. Adding different amounts of $\mathrm{GdCl}_{3} \cdot 6 \mathrm{H}_{2} \mathrm{O}$, one 


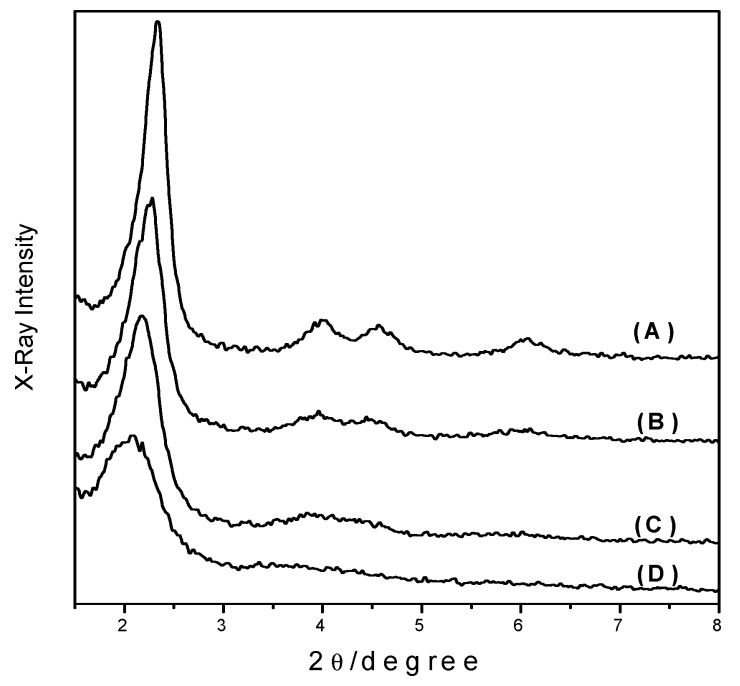

Figure 1. XRD of nanosized Gd-MS with different Gd loading: (A) $0 \%$, (B) $2.3 \%$, (C) $3.1 \%$, and (D) $6.8 \%$.

can obtain various Gd-loaded mesoporous silica (MS). The products are denoted as $\mathrm{X} \% \mathrm{Gd}-\mathrm{MS}$ ( $\mathrm{X}$ is the amount of $\mathrm{Gd}$ in mesoporous silica).

Characterization. X-ray powder diffraction patterns (XRD) were acquired with a Scintag $\times 1$ diffractometer $(40 \mathrm{kV}, 30 \mathrm{~mA})$ with $\mathrm{Cu} K \alpha$ radiation. The nitrogen adsorption-desorption isotherms, surface area, and pore size distribution (BJH method) were obtained at $77 \mathrm{~K}$ with a Micromeritics ASAP 2010 analyzer. High-resolution transmission electron micrographs (HRTEM) were recorded with a JEOL JEM-2010 at an acceleration voltage of $200 \mathrm{kV}$. X-ray photoelectron spectroscopy measurements (XPS) were performed on a Thermo VG Scientific, ESCALAB 250 equipped with monochromatic Al $\mathrm{K} \alpha$ as radiation source. ${ }^{29} \mathrm{Si}-\mathrm{MAS}$ NMR spectra were recorded at room temperature with a Bruker MSL500 spectrometer. The amount of gadolinium in the product was determined with a Perkin-Elmer Elan-6000 inductively coupled plasma mass spectrometer (ICP-MS). The longitudinal and transverse relaxation times, $T_{1}$ and $T_{2}$, were measured at $400 \mathrm{MHz}$ with a Unity INOVA from Varian. Samples were suspended in $0.2 \%$ xanthan gum. For $T_{1}$ measurements, the standard inversion-recovery (IR) method was used as the pulse sequence. The recycle delay time was set to five times the $T_{1}$ value. Typically 12 points were taken for each $T_{1}$ measurement. For $T_{2}$ measurements, the Carr-Pucell-Meiboom-Gill (CPMG) method was used. The $T_{1}$-weighted phantom images were obtained on a $4.7 \mathrm{~T}$ Biospec spectrometer (DBX Avance 47/40, Bruker, Karlsruhe, Germany) by the conventional spin-echo method with TR/TE $=300 \mathrm{~ms} /$ $10.6 \mathrm{~ms}, \mathrm{FOV}=7 \mathrm{~cm}, \mathrm{NEX}=1, \mathrm{BW}=100000 \mathrm{~Hz}$, slice thickness $=2.00 \mathrm{~mm}$, matrix $=256 \times 256$, and temperature $=$ $20{ }^{\circ} \mathrm{C}$

The stability was tested by soaking Gd-MS in a $\mathrm{pH} 7.4$ solution at $37.5{ }^{\circ} \mathrm{C}$ for $24 \mathrm{~h}$. After being centrifuged the supernatant was adjusted to $\mathrm{pH} 4$ with sodium acetate buffer and titrated with $0.01 \mathrm{M}$ EDTA with xylenol orange as an indicator.

\section{Results and Discussion}

Gadolinium-loaded Gd-MS were synthesized with use of cationic long chain surfactant as a template. Because gadolinium hydroxide would form and precipitate out under basic condition, $\mathrm{C}_{16} \mathrm{TAB}$ surfactant, $\mathrm{GdCl}_{3} \cdot 6 \mathrm{H}_{2} \mathrm{O}$, and TEOS were mixed under acidic condition and after hydrolysis of TEOS the product GdMS was precipitated out by raising the $\mathrm{pH}$ to 9 with $\mathrm{NH}_{4} \mathrm{OH}$.

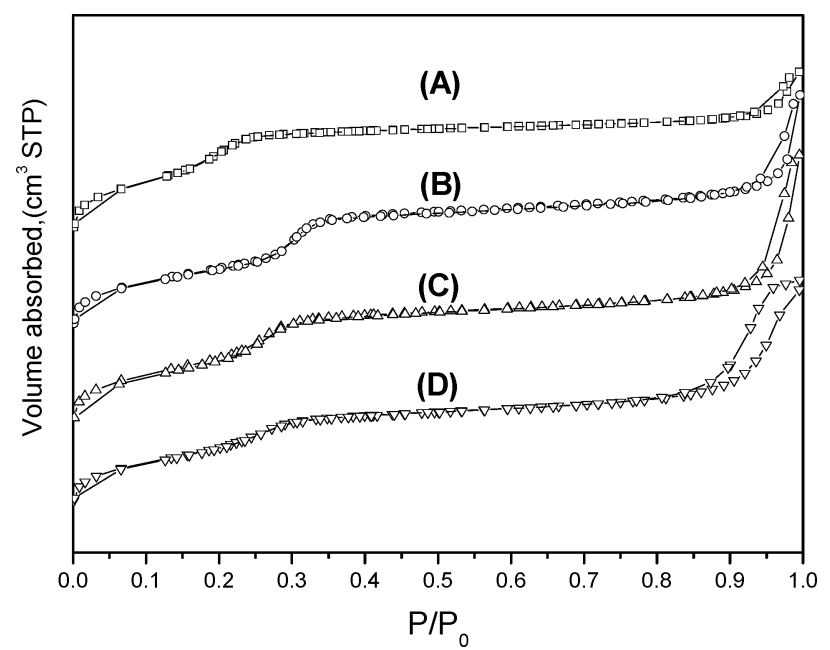

Figure 2. N2 adsorption-desorption isotherms of nanosized Gd-MS with different Gd loading: (A) $0 \%$, (B) $2.3 \%$, (C) $3.1 \%$, and (D) $6.8 \%$.

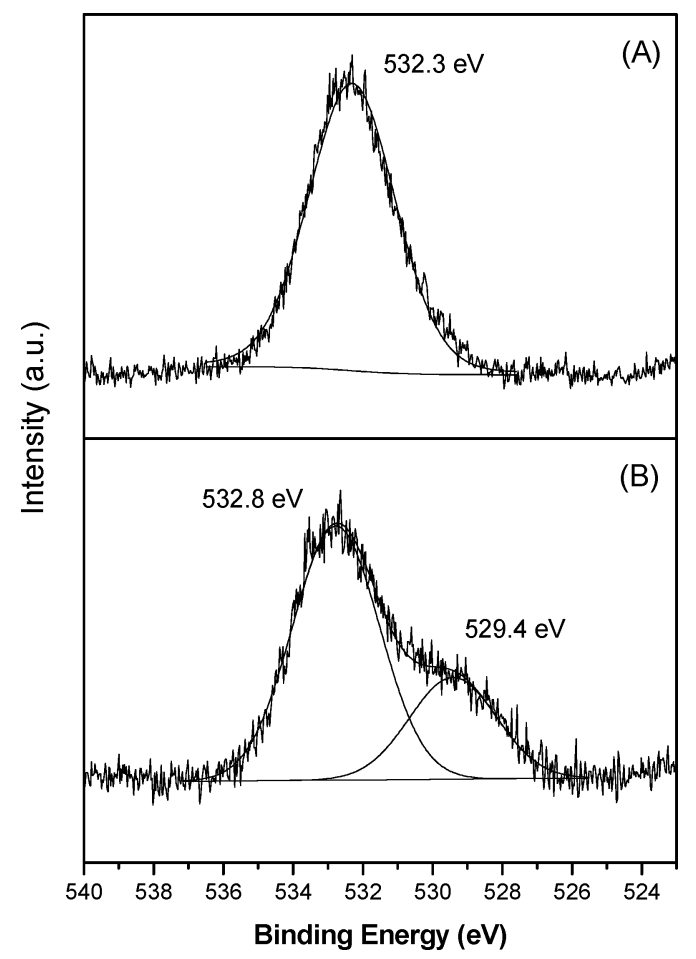

Figure 3. O 1s XPS spectra of (A) pure siliceous MS and (B) $6.8 \% \mathrm{Gd}-$ MS.

This is a simple and fast method in contrast to reported methods of the syntheses of Tb-MCM 41 and Eu-MS, ${ }^{10,11}$ where an interface growth and a basic condition synthesis followed by hydrothermal conditions for $40 \mathrm{~h}$ were employed, respectively. In the synthesis, the solution was in a highly diluted condition such that the resulting particle size of Gd-MS is in the nanometer range. ${ }^{12}$ This is shown in the SEM image (Figure S1, Supporting Information).

The periodic and porous nature of the product was confirmed by XRD and nitrogen adsorption-desoprtion isotherms. Typical XRD and $\mathrm{N}_{2}$ adsorption-desorption isotherms are shown in Figures 1 and 2. The XRD patterns in Figure 1 are similar to that of pristine MCM-41. ${ }^{13}$ Also no crystalline $\mathrm{Gd}_{2} \mathrm{O}_{3}$ peaks were detected in the high-angle portion of the XRD pattern. The XRD patterns of different amounts of Gd(III)-incorporated samples show the 2-D hexagonal porous structure, and the gradual broadening of peaks also reveals that the structure ordering decreases as the loading of Gd(III) increases, and the 


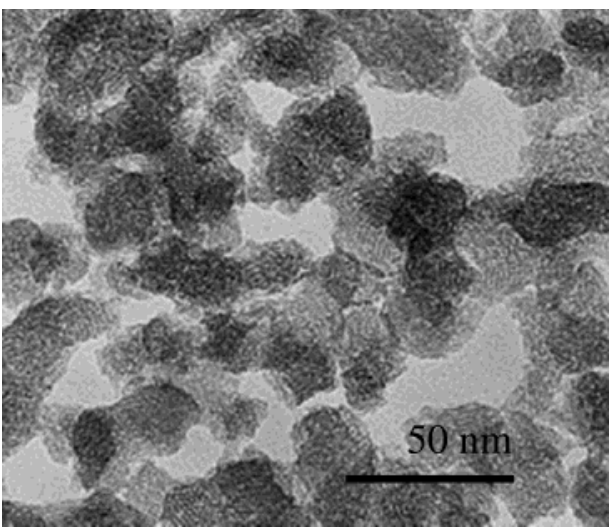

Figure 4. HRTEM of $2.3 \%$ Gd-MS nanoparticles. The scale bar is 50 nm.

pore structure changes from 2-D hexagonal ordered pores to wormlike pores. This result also provides indirect evidence that $\mathrm{Gd}(\mathrm{III})$ is indeed incorporated into the mesoporous silica framework.

The $\mathrm{N}_{2}$ adsorption-desorption isotherm shows a pore size distribution around $2 \mathrm{~nm}$ as calculated according to the $\mathrm{BJH}$ method. The sharp uptake near $P \approx P_{\mathrm{o}}$ is attributed to textural porosity produced by the interparticle nanospace. All the GdMS silicas possess high surface area, $\sim 1000 \mathrm{~m}^{2} \mathrm{~g}^{-1}$, and high textural porosity. That Gd(III) is incorporated in the framework is further evidenced by the $\mathrm{O} 1 \mathrm{~s}$ peak in the XPS spectrum. Comparing to the pure siliceous MS, the $\mathrm{O} 1 \mathrm{~s}$ peak of $6.8 \% \mathrm{Gd}-$ MS is broadened and the shoulder at lower energy is salient. This shift indicates Gd is incorporated into the framework replacing Si. ${ }^{14}$ Two peaks (at 532.8 and $529.4 \mathrm{eV}$ ) could be resolved for the $\mathrm{O} 1 \mathrm{~s}$ peak (Figure 3). Using pristine MS as a reference, the extra shoulder peak at $529.4 \mathrm{eV}$ is assigned to the $\mathrm{O}$ atom between $\mathrm{Si}$ and $\mathrm{Gd}$. To our knowledge this is the first example of using XPS to characterize lanthanideincorporated mesoporous silica. The ${ }^{29} \mathrm{Si}-\mathrm{MAS}$ NMR spectrum of $6.8 \% \mathrm{Gd}$ -

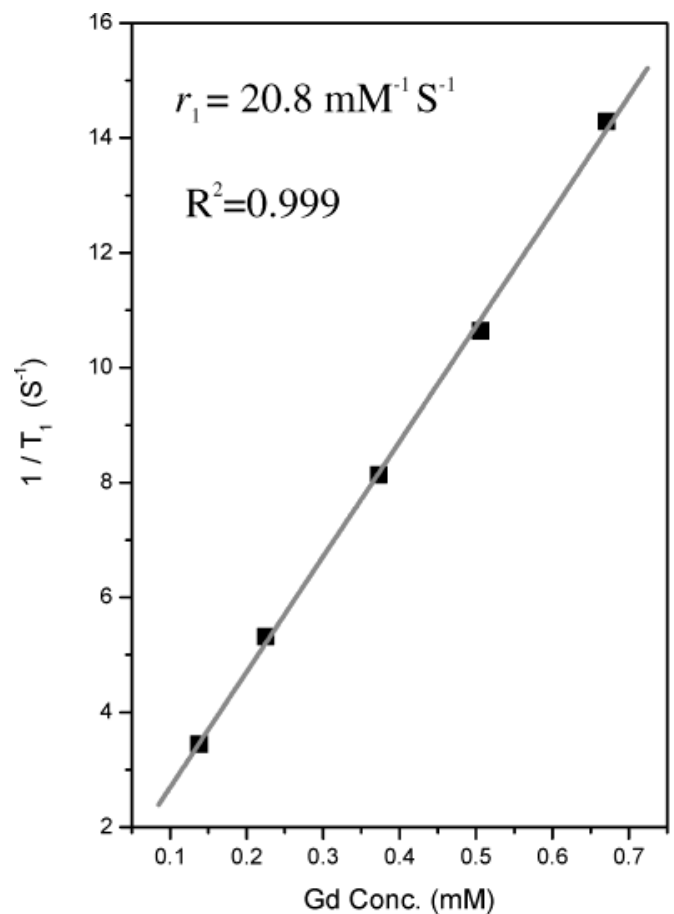

TABLE 1: Relaxivities of Gd-MS at $9.4 \mathrm{~T}^{a}$

\begin{tabular}{lcc}
\hline \multicolumn{1}{c}{ sample } & $r_{1}\left(\mathrm{mM}^{-1} \mathrm{~s}^{-1}\right)$ & $r_{2}\left(\mathrm{mM}^{-1} \mathrm{~s}^{-1}\right)$ \\
\hline $1.6 \%$ Gd-MS & 23.6 & 94.8 \\
2.3\%Gd-MS & 20.8 & 82.3 \\
$3.1 \%$ Gd-MS & 7.2 & 85.1 \\
$6.8 \%$ Gd-MS & 4.4 & 80.4 \\
{$\left[\text { Gd(DTPA) }\left(\mathrm{H}_{2} \mathrm{O}\right)\right]^{2-}$} & 3.9 & 4.3 \\
$\mathrm{Gd}_{\mathrm{aq}}{ }^{3+}$ & 9.5 & 10.5
\end{tabular}

${ }^{a}$ The proton relaxivities $r_{1}$ and $r_{2}$ were determined at $400 \mathrm{MHz}, 23$ ${ }^{\circ} \mathrm{C}$, and $\mathrm{pH} 7$; the corresponding relaxivities of $\mathrm{Gd}(\mathrm{III})$ ion and $[\mathrm{Gd}(\mathrm{DTPA})(\mathrm{H} 2 \mathrm{O})]^{2-}$ are shown for comparison. Samples were suspended in $0.2 \%$ xanthan gum.

MS (not shown) also shows a weak extra shoulder at lower field compared to pristine MS, also indicating $\mathrm{Gd}$ is in the framework. ${ }^{10}$ The HRTEM image (Figure 4) of $2.3 \% \mathrm{Gd}-\mathrm{MS}$ shows that the particle shape is nonspherical with dimensions less than $100 \mathrm{~nm}$. However, some aggregation did occur. The materials are stable; no metal leaching was detected at $37.5^{\circ} \mathrm{C}$ after $24 \mathrm{~h}$ at $\mathrm{pH} 7.4$ nor in the presence of $0.25 \mathrm{M} \mathrm{Ca}$ (II) under the same conditions, which is important for biological applications.

The proton relaxivities, $r_{1}$ and $r_{2}$, of Gd-MS were determined at $400 \mathrm{MHz}$. For $T_{1}$ measurements, the standard inversionrecovery (IR) method was used as the pulse sequence; and for $T_{2}$ measurements, the Carr-Pucell-Meiboom-Gill (CPMG) method was used. Typical $r_{1}$ and $r_{2}$ plots are shown in Figure 5. Relaxivity data are listed in Table 1. All Gd-MS samples show better longitudinal relaxivity, $r_{1}$, and transverse relaxivity, $r_{2}$, than $\left[\mathrm{Gd}(\mathrm{DTPA})\left(\mathrm{H}_{2} \mathrm{O}\right)\right]^{2-}$. However, the $r_{1}$ values of various Gd-loaded Gd-MS (from $1.3 \%$ to 6.8 wt $\%$ ) decrease abruptly as the Gd loading increases from $2.3 \%$ to $3.1 \%$, and the range is between 4.4 and $23.6 \mathrm{mM}^{-1} \mathrm{~s}^{-1}$ at $400 \mathrm{MHz}$ and $23{ }^{\circ} \mathrm{C}$. This drastic change of relaxivity with the $\mathrm{Gd}^{3+}$ loading was also reported for zeolite $\mathrm{GdNaY}$ nanoparticles where the range is between 11.4 and $37.7 \mathrm{mM}^{-1} \mathrm{~s}^{-1}$ at $60 \mathrm{MHz}$ and $37{ }^{\circ} \mathrm{C}$. ${ }^{9 \mathrm{a}}$ Presumably at high $\mathrm{Gd}$ loading the dipole-dipole interaction

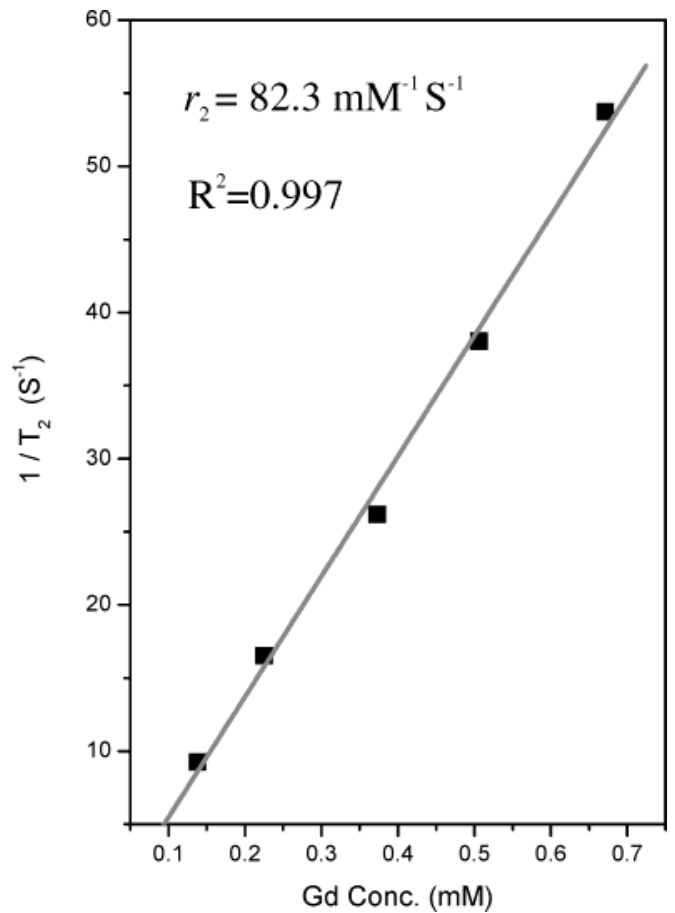

Figure 5. The proton relaxivities, $r_{1}$ and $r_{2}$, of $2.3 \% \mathrm{Gd}-\mathrm{MS}$ determined at $400 \mathrm{MHz}$ with a Unity INOVA from Varian. For $T_{1}$ measurements, the standard inversion-recovery (IR) method was used as the pulse sequence. For $T_{2}$ measurements, the Carr-Pucell-Meiboom-Gill (CPMG) method was used. 


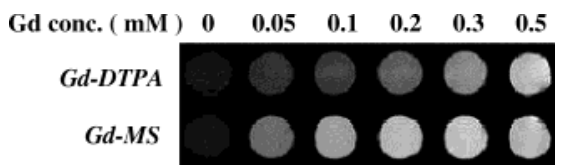

Figure 6. $T_{1}$-weighted phantom MR image of Gd-DTPA, $2.3 \% \mathrm{Gd}$ MS, and water $(\mathrm{Gd}$ concentration $=0 \mathrm{mM})$ at $4.7 \mathrm{~T}$ Bruker by the conventional spin - echo method with TR/TE $=300 \mathrm{~ms} / 10.6 \mathrm{~ms}$, FOV $=7 \mathrm{~cm}, \mathrm{NEX}=1 ; \mathrm{BW}=100000 \mathrm{~Hz}$, slice thickness $=2.00 \mathrm{~mm}$, matrix $=256 \times 256$, and temperature $=20^{\circ} \mathrm{C}$.

among the metal ions becomes more significant, and the electronic relaxation shortens. This is supported by the relaxivity data of mixed metal nanoparticles, Eu-Gd-MS (Table S1, Supporting Information). The relaxivity drops drastically when $\mathrm{Eu}(\mathrm{III})$ was added in spite of the amount of Gd remaining the same. On the contrary, $r_{2}$ is relatively insensitive to the loading, with a range of only 95 to $80 \mathrm{mM}^{-1} \mathrm{~s}^{-1}$; it also shows a similar trend, as the loading increases $r_{2}$ decreases. Initial results on the field dependence of $r_{1}$ and $r_{2}$ show that $r_{2}$ is highly sensitive to the magnetic field (for $2.3 \% \mathrm{Gd}-\mathrm{MS} r_{2}$ is $30 \mathrm{mM}^{-1} \mathrm{~s}^{-1}$ at 20 $\mathrm{MHz}$ and $82 \mathrm{mM}^{-1} \mathrm{~s}^{-1}$ at $400 \mathrm{MHz}$ and $23{ }^{\circ} \mathrm{C}$ ), whereas $r_{1}$ is insensitive to the field. The apparent dependence of $r_{2}$ on the magnetic resonance frequency may be attributed to the so-called Curie spin relaxation. ${ }^{15}$ In vitro $T_{1}$-weighted phantom images were obtained with $2.3 \% \mathrm{Gd}-\mathrm{MS}$ with a $4.7 \mathrm{~T}$ Biospec spectrometer (see Figure 6 ). In the $T_{1}$-weighted imaging sequence, as the amount of Gd-MS increases the $T_{1}$ images lighten up faster than those of the corresponding $\left[\mathrm{Gd}(\mathrm{DTPA})\left(\mathrm{H}_{2} \mathrm{O}\right)\right]^{2-}$ implying Gd-MS is a better relaxivity enhancer. With $T_{2^{-}}$ weighted imaging, the opposite was observed; that is, the image darkens as the concentration increases, and again the effect of Gd-MS is more than that of $\left[\mathrm{Gd}(\mathrm{DTPA})\left(\mathrm{H}_{2} \mathrm{O}\right)\right]^{2-}$.

We also note that since the sol-gel chemistry of $\mathrm{Eu}, \mathrm{Tb}$, and Gd is essentially the same, our mesoporous silica MS can be easily codoped with the above lanthanides as shown in the data presented in the Supporting Information. Strong and sharp luminescence spectra can be easily obtained from Eu(III) (red) and $\mathrm{Tb}(\mathrm{III})$ (green) in the visible range. The codoped $\mathrm{Eu}-\mathrm{Tb}-$ Gd MS nanoparticle system may thus serve in a multifunctional biological imaging system where simultaneous MRI and luminescence imaging are employed.

\section{Conclusions}

In conclusion we have synthesized Gd(III)-incorporated mesoporous silica nanoparticles. Gd-MS displays much higher relaxivity than $\left[\mathrm{Gd}(\mathrm{DTPA})\left(\mathrm{H}_{2} \mathrm{O}\right)\right]^{2-}$; this is likely because more than one water can be coordinated to metal and a substantial decrease of the Gd metal ion rotational motion in the framework. The observed high $r_{1}$ and $r_{2}$ values, nanosize, and easy derivatization of silica make Gd-incorporated mesoporous silica a versatile new class of MRI contrast agent. Other lanthanides may be incorporated into mesoporous silica easily with use of this method. Mesoporous silica with mixed Gd and Eu (red emitter) or $\mathrm{Gd}$ and $\mathrm{Tb}$ (green emitter) on the wall were also synthesized by the same method, and the materials have dual imaging functions, MRI, and fluorescence. Since the lanthanides have large Stokes shifts, display sharp emission spectra, and have a long lifetime, the mixed materials have added advantages of fluorescence imaging. In recent years, the high pore volume of mesoporous silica has been investigated as a drug delivery agent with gated control. ${ }^{8}$ Our development of lanthanide-loaded nanosized mesoporous silica may help toward the goal of dual imaging capability. Together with gate control and surface functionalization, these materials can serve as a targeted drug delivery system with visualization.

Acknowledgment. This work was supported by a grant from the Ministry of Education of Taiwan through the Academy Excellency program. The support of the Functional and Micromagnetic Resonance Imaging Core Facility, Taiwan, under the National Science and Technology program for Genomic Medicine is also acknowledged. We thank Dr. S. J. Huang for taking the ${ }^{29}$ Si-MAS NMR spectra. Prof. H. P. Lin and Ms. M. C. Chao are thanked for discussing the synthesis method.

Supporting Information Available: Typical SEM image of Gd-MS and table of the relaxivities of Eu-Gd-MS at 9.4 T. This material is available free of charge via the Internet at http:// pubs.acs.org.

\section{References and Notes}

(1) Gries, H. Top. Curr. Chem. 2002, 221, 1.

(2) (a) Caravan, P.; Ellison, J. J.; McMurry, T. J.; Lauffer, R. B. Chem. Rev. 1999, 99, 2293. (b) Lauffer, R. B. Chem. Rev. 1987, 87, 901.

(3) Merbach, A. E.; Toth, E. The Chemistry of Contrast Agents in Medical Magnetic Resonance Imaging; John Wiley \& Sons: New York, 2001.

(4) Rummeny, E.; Ehrenheim, CH.; Gehl, H. B.; Hamm, B.; Laniado, M.; Lodemann, K. P.; Schmiedel, E.; Steudel, A.; Vogl, TH. G. Invest. Radiol. 1991, 26, S142.

(5) Jung, C. W.; Jacobs, P. Magn. Reson. Imaging 1995, 13, 661.

(6) Weinmann, H.-J.; Ebert, W.; Misselwitz, B.; Schmitt-Willich, H. Eur. J. Radiol. 2003, 46, 33

(7) (a) Massound, T. F.; Gambhir, S. S. Genes Dev. 2003, 17, 545. (b) Weissleder, R. Nature Rev. Cancer 2002, 2, 1. (c) Ciobanu, L.; Webb, A. G.; Pennington, C. H. Prog. Nucl. Magn. Reson. Spectrosc. 2003, 42, 69.

(8) (a) Mal, N. K.; Fujiwara, M.; Tanaka, Y. Nature 2003, 421, 350. (b) Lai, C.-Y.; Trewyn, B. G.; Jeftinija, D. M.; Jeftinija, K.; Xu, S.; Jeftinija, S.; Lin, V. S.-Y. J. Am. Chem. Soc. 2003, 125, 4451.

(9) (a) Platas-Iglesias, C.; Vander Elst, L.; Zhou, W.; Muller, R. N.; Geraldes, C. F. G. C.; Maschmeyer, T.; Peters, J. A. Chem. Eur. J. 2002, 8, 5121. (b) Bresinska, I.; Balkus, K. J., Jr. J. Phys. Chem. 1994, 98, 12989. (c) Sur, S. K.; Heinsbergen, J. F.; Bryant, R. G. J. Magn. Reson., Ser. A 1993, 103, 27

(10) Yin, W.; Zhang, M. J. Alloys Compd. 2003, 360, 231.

(11) Matos, J. R.; Mercuri, L. P.; Jaroniec, M.; Kruk, M.; Sakamoto, Y.; Terasaki, O. J. Mater. Chem. 2001, 11, 2580.

(12) Lin, H. P.; Tsai, C. P. Chem. Lett. 2003, 32, 1092.

(13) Beck, J. S.; Vartuli, J. C.; Roth, W. J.; Leonowicz, M. E.; Kresge, C. T.; Schmitt, K. D.; Chu, C. T.-W.; Olson, D. H.; Sheppard, E. W. McCullen, S. B.; Higgins, J. B.; Schlenker, J. L. J. Am. Chem. Soc. 1992, 114,10834 .

(14) (a) Stakheev, A. Y.; Shpiro, E. S.; Apijok, J. J. Phys. Chem. 1993 97, 5668. (b) Rodríguez-Castellón, E.; Jiménez-López, A.; Maireles-Torres, P.; Jones, D. J.; Rozière, J.; Trombetta, M.; Busca, G.; Lenarda, M.; Storaro, L. J. Solid State Chem. 2003, 175, 159.

(15) Gueron, M. J. Magn. Reson. 1975, 19, 58. 